\title{
Explaination of water scarcity situation for Hebei Province Tong Li
}

Department of Electrical and Electronic Engineering, North China Electric Power University, Baoding071000, Hebei Province,China; Email: 531875450@qq.com

Keywords: water scarcity, R-type clustering method, Principal Component Analysis

\begin{abstract}
Hebei as our example to find its water scarcity situation. R-type clustering method is developed to divide the factors of physical and economic scarcity into four parts, hydropower construction investment, effective irrigation area, water consumption per capita and other reasons. Then we invoke Principal Component Analysis(PCA) to determine the weight of each factor. We find the backward hydropower construction situation mainly causes the water scarcity.
\end{abstract}

\section{Introduction}

First, the region of Hebei, where water is heavily overloaded, is chosen to be an example for us. Considering the severely lack of water, it's of great significance to explain why and how water is scarce.

The scarcity is divided into two parts.

- Physical scarcity, which indicates that the region lacks water. Thus we use other water content and water consumption per capita to describe it.

$>$ Other water content is the amount of water that should be transported from other regions. In other words, the value increases with the rise of scarcity scale. Let $O$ denotes other water content, it can be calculated as:

$$
O=D-Y
$$

$>$ Water consumption per capita shows the amount of water that can be used for each person. So it can also reflect the situation of physical scarcity.

- Economic scarcity, which indicates the water exists but poor management and deficient infrastructure limits it. Hydropower construction investment, effective irrigation area, wastewater discharge amount and Gross Domestic Product are four aspects to be considered.

$>$ Hydropower construction investment, effective irrigation area: the indexes reflect the situation of infrastructure construction.

$>$ Wastewater discharge amount can easily describe the management sate. If there is a better manage, there will be less wastewater discharge.

$>$ Gross Domestic Product demonstrates the development tendency of the region, which reflects whether there is economic scarcity.

\section{R-type clustering method}

To properly explore "why water is scarce", R-type clustering method(RCM) ${ }^{[1]}$ is employed. Through the clustering method, we can aggregate the above six factors and find out several main factors.

\subsection{Clustering process}

- Determine correlation coefficient

We regard two of above six factors as variate $x_{j}(j=1,2,3,4,5,6)$ and $x_{k}(k=1,2,3,4,5,6)$. Then, we define that:

$$
\left(x_{1 j}, x_{2 j}, \cdots, x_{n j}\right)^{T} \in R^{n}
$$


Here we obtain the correlation coefficient:

- Variables cluster

$$
r_{j k}=\frac{\sum_{i=1}^{n}\left(x_{i j}-\bar{x}_{j}\right)\left(x_{i k}-\bar{x}_{k}\right)}{\left[\sum_{i=1}^{n}\left(x_{i j}-\bar{x}_{j}\right)^{2} \sum_{i=1}^{n}\left(x_{i k}-\bar{x}_{k}\right)^{2}\right]^{\frac{1}{2}}}
$$

We define the distance of two kind of variables as:

$$
R\left(G_{1}, G_{2}\right)=\min _{\substack{x_{j} \in G_{1} \\ x_{k} \in G_{2}}}\left\{d_{j k}\right\}
$$

Where $d_{i j}=1-\left|r_{j k}\right|$.

\subsection{Results and analysis}

The relevant data searched from official website of Hebei Provincial Department of Water Resources $^{[2]}$ are used to experiment. The result is showed in the following figure:

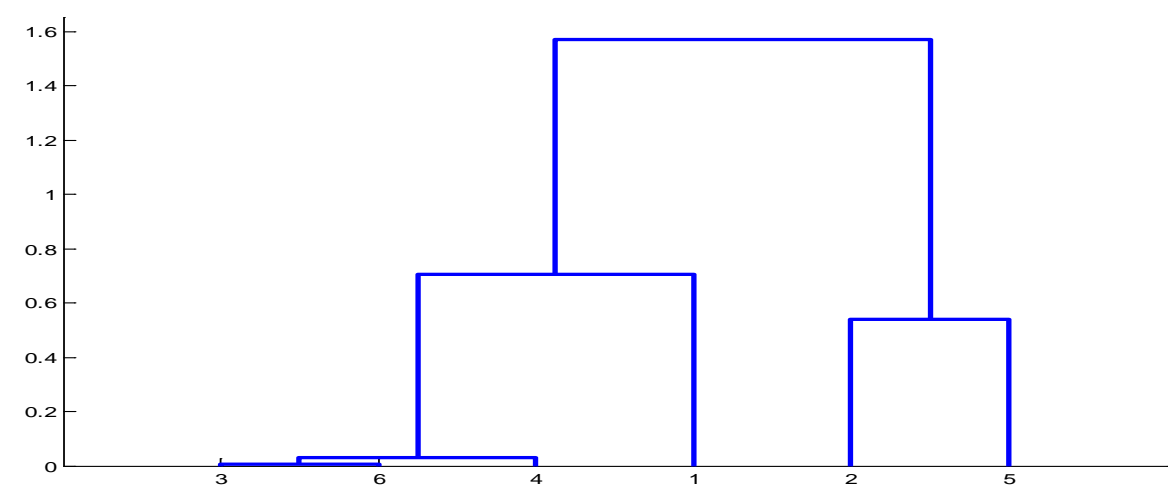

Fig. 1 The result of R-type clustering method

“1”,“2”,“3”,“4”,“5”,“6” refer to “hydropower construction investment”,"Effective irrigation area”,"Wastewater discharge amount”,“Other water content”, “Water consumption per capita”and "Gross Domestic Product”, respectively.

From the figure above, we conclude that wastewater discharge amount, wther water content and Gross Domestic Product can be aggregated together while the other three factors are not that similar. Namely, these four main factors are the answers to "why water is scarce?".

\section{Principal Component Analysis}

In order to obtain the weight of each index, Principal Component Analysis(PCA $)^{[1]}$ is utilized. It is a statistical procedure that uses an orthogonal transformation to convert a set of observations of possibly correlated variables into a set of values of linearly uncorrelated variables called principal components. ${ }^{[3]}$

\subsection{Analysis process}

- Determine the design matrix

We define $a_{i 1}, a_{i 2}, \cdots, a_{i p}, i=1,2, \cdots, n$ as the value of six factors in $i$ year. Then design matrix (A) is obtained.

- Standardize the data

$$
A=\left[\begin{array}{cccc}
a_{11} & a_{12} & \ldots & a_{1 p} \\
a_{21} & a_{22} & \ldots & a_{2 p} \\
\vdots & \vdots & & \vdots \\
a_{n 1} & a_{n 2} & \ldots & a_{n p}
\end{array}\right]
$$

Standardize the data through equation $\tilde{x}_{i}=\left(x_{i}-\mu_{i}\right) / \sigma_{i}$, then we get the standardized data matrix $\tilde{A}$. Moreover, correlation matrix $R$ is obtained under the expression $R=\widetilde{A}^{T} \tilde{A} /(n-1)$. 
- Consider the weight

In this step, we try to explore the contribution principle component made to original variable. Here we use the equation $\ell_{i}=\sum_{j=1}^{r} r^{2}\left(z_{j}, x_{i}\right)$.

\subsection{Results and Analysis}

Address the data with PCA and the weight of each factors are obtained. The results are presented in Table 1.

Table 1 The weight of six factors

\begin{tabular}{|c|c|c|c|c|c|c|}
\hline & 1 & 2 & 3 & 4 & 5 & 6 \\
\hline Weight & 70.28540 & 17.44039 & 1.086745 & 0.259053 & 10.83144 & 0.096947 \\
& 988 & 979 & 177 & 334 & 473 & 09 \\
\hline
\end{tabular}

Where “1”,“2”,“3”,“4”,“5”,“6” have the same meanings in Figure 4.1.

According to above table, we find that hydropower construction has the biggest weight. Besides, effective irrigation area and water consumption per capita take behind in the weight of 17.44 and 10.83 respectively. For the rest of three, the sum of their weight nearly equals to 1 .

For region of Hebei, the infrastructure deficiency, especially the backward hydropower construction situation mainly causes the water scarcity. It's also relatively obvious to be reflected in the aspect of effective irrigation area shortage.

\section{Conclusion}

- Wastewater discharge amount, wther water content and Gross Domestic Product can be aggregated together while the other three factors are not that similar.

- For Hebei, the infrastructure deficiency, especially the backward hydropower construction situation mainly causes the water scarcity. It's also relatively obvious to be reflected in the aspect of effective irrigation area shortage.

\section{References}

[1]Si Shoukui,Sun Xijing,Mathematical Modeling,National Defense Industry press,June 2014,Pages 358-363,Pages 131-140

[2]Information on:http://www.hebwater.gov.cn/

[3]Qiyuan Jiang,Jinxing Xie,Jun Ye,(2010)Mathematical Models,Higher Education

Press,ISBN 978-7-04-031150-1 